\title{
A Disintegrin and Metalloproteinase with Thrombospondin Motifs 18 Deficiency Leads to Visceral Adiposity and Associated Metabolic Syndrome in Mice
}

Rui Zhu, ${ }^{*}$ Mengting Cheng, ${ }^{*}$ Tiantian Lu, ${ }^{*}$ Ning Yang,${ }^{*}$ Shuai Ye, ${ }^{*}$ Yi-Hsuan Pan, ${ }^{*}$ Tao Hong, ${ }^{*}$ Suying Dang, ${ }^{\dagger}$ and Wei Zhang

From the Key Laboratory of Brain Functional Genomics, * Ministry of Education, Shanghai Key Laboratory of Brain Functional Genomics, School of Life Sciences, East China Normal University, Shanghai; the Department of Biochemistry and Molecular Cell Biology, ${ }^{\dagger}$ Shanghai Jiao Tong University School of Medicine, Shanghai; and the Shanghai Research Center for Model Organisms, ${ }^{\ddagger}$ Shanghai, Republic of China

\author{
Accepted for publication \\ October 19, 2017 \\ Address correspondence to Wei \\ Zhang, Ph.D., East China \\ Normal University, $3663 \mathrm{~N}$ \\ Zhongshan Rd, Shanghai \\ 200062, China; or Suying \\ Dang, Ph.D., Shanghai Jiao \\ Tong University School of \\ Medicine, 227 S Chongqing \\ Rd, Shanghai 200025, \\ China. E-mail: wzhang@sat. \\ ecnu.edu.cn or suyingdang@ \\ shsmu.edu.cn.
}

\begin{abstract}
Visceral adiposity is of greater risk than obesity in s.c. adipose tissue for diabetes and cardiovascular disease. Its pathogenesis remains unclear, but it is associated with extracellular matrix (ECM) remodeling. A disintegrin and metalloproteinase with thrombospondin motifs (ADAMTSs) are a family of secreted zincdependent metalloproteinases that play crucial roles in development and various diseases because of their ECM remodeling activity. ADAMTS18 is an orphan ADAMTS whose function and substrate remain unclear. Herein, we showed that Adamts18 mRNA was abundantly expressed in visceral (gonadal) white adipose tissue (vWAT) during the early stage of development after birth. Adamts18 knockout (K0) mice showed increased body fat percentage and larger adipocyte size in vWAT relative to wild-type littermates. These findings may be partly attributed to ECM remodeling, especially increased expression of laminin 1 and adipokine thrombospondin 1 in vWAT. Attenuated extracellular signal-regulated kinase 1 and 2 activity, along with increased expression of adipocyte-specific transcription factors peroxisome proliferatoractivated receptor- $\gamma$, CCAAT/enhancer binding protein $\beta$, and marker gene Fabp4, was detected in vWAT of Adamts18 K0 mice. Furthermore, Adamts18 K0 mice showed early metabolic syndrome, including hyperlipidemia, blood glucose metabolic disorder, and hypertension. ADAMTS18 deficiency promotes atherosclerosis in apolipoprotein $\mathrm{E}$-deficient mice. These results indicate a novel function of ADAMTS18 in vWAT development and associated metabolic disorders. (Am J Pathol 2018, 188: 461-473; https:// doi.org/10.1016/j.ajpath.2017.10.020)
\end{abstract}

Adipose tissue consists of adipocytes, stromal vascular fraction (SVF) cells, including preadipocytes, endothelial cells, fibroblasts, and macrophages, and extracellular matrix (ECM), such as collagen (Col) and laminin. ${ }^{1-3}$ ECM provides a critical microenvironment for adipocyte development and the phenotypic fate of mesenchymal stem cells. ${ }^{4,5}$ Adipocyte-ECM cross talk dysfunction may lead to lipid metabolism disorders, including abdominal (central) obesity, high serum triglycerides (TGs), abnormal glucose (GLU) regulation, and elevated blood pressure. ${ }^{6,7}$ Thus, identifying key molecules that orchestrate adipose tissue ECM is crucial for understanding the molecular basis of obesity and associated metabolic diseases.
A disintegrin and metalloproteinase with thrombospondin motifs (ADAMTSs) are a family of 19 secreted zinc metalloendopeptidases, which are known to cleave a wide range of substrates in ECM and have been implicated in development, tissue morphogenesis and remodeling, inflammation, tumorigenesis, and vascular biology. ${ }^{8-10}$ The functions of ADAMTSs include N-terminal procollagen

Supported by the National Natural Science Foundation of China grants 81570389 and 81170481 (W.Z.) and 81200352 (S.D.) and the Shanghai Municipal Natural Science Foundation grant 16ZR1423700 (S.D.).

R.Z. and M.C. contributed equally to this work.

Disclosures: None declared. 
Table 1 Primary Antibodies Used in this Study

\begin{tabular}{llll}
\hline No. & Product name & Application & Source \\
\hline 1 & p38 MAPK antibody & WB & CST (Boston, MA; 9212) \\
2 & Phospho-p38 MAPK & WB & CST (9211) \\
& (Thr180/Tyr182) antibody & & CST (9102) \\
3 & p44/42 MAPK (ERK1/2) antibody & WB & CST (9101) \\
4 & Phospho-p44/42 MAPK (ERK1/2) & WB & Abcam (Cambridge, UK; ab191407) \\
5 & (Thr202/Tyr204) antibody & WB & Abcam (ab32358) \\
6 & Anti-PPAR $\gamma$ & WB & Abcam (ab108311) \\
7 & Anti-C/EBPB & WB & Abways (Shanghai, China; AB0037) \\
8 & Anti-aP2 & WB & Anti-GAPDH
\end{tabular}

aP2, adipocyte protein 2; C/EBP $\beta$, CCAAT/enhancer binding protein $\beta$; ERK1/2, extracellular signal-regulated kinase 1 and 2; GAPDH, glyceraldehyde-3phosphate dehydrogenase; MAPK, mitogen-activated protein kinase; PPAR $\gamma$, peroxisome proliferator-activated receptor- $\gamma$; WB, Western blotting.

processing (ADAMTSs 2, 3, and 14) ${ }^{11-14}$; spermatogenesis (ADAMTS2) $^{15}$; follicular rupture and ovulation $\left(\right.$ ADAMTS1) ${ }^{16}$; angiogenesis inhibition (ADAMTSs 1,8 , and 9$)^{17,18}$; degradation of cartilage oligomeric matrix protein (ADAMTSs 7 and 12) ${ }^{19}$; cleavage of the matrix proteoglycan aggrecan, versican, and brevican (ADAMTSs 1, 4, 5, 8, 9, and $15)^{20-23}$; and cleavage of ultralarge-molecular-weight von Willebrand factor (ADAMTS13). ${ }^{24}$ Recent reports have shown that some ADAMTSs play crucial roles in adipogenesis and metabolic disorders. It was found that ADAMTS1 was decreased in the adipose tissue of obese mice, and ADAMTS1 inhibition increased adipose tissue mass via the ECM-dependent focal adhesion kinase/extracellular signal-regulated kinases 1 and $2(E R K 1 / 2)$ signaling pathway. ${ }^{25}$ In humans, ADAMTS1 level is inversely related to body mass index. ${ }^{25}$ In addition, a population-based cohort study showed that ADAMTS13 activity may be an independent risk factor for incident prediabetes and type 2 diabetes. ${ }^{26}$ Furthermore, ADAMTS5 promoted murine adipogenesis and the development of visceral (gonadal) white adipose tissue (vWAT) and associated angiogenesis. ${ }^{27}$ Moreover, loss of ADAMTS5 enhances brown adipose mass and promotes browning of white adipose tissue via cAMP response element-binding protein signaling in mice. $^{28}$

ADAMTS18 is an orphan ADAMTS whose function and substrate remain unclear. In C57B16/Ola mice, Adamts 18 deletion results in distinct developmental defects, including congenital disorders of the lens, lung, and female reproductive tract development. ${ }^{29}$ In humans, ADAMTS18 mutations have been linked to tumorigenesis, ${ }^{30}$ eye diseases, ${ }^{31-33}$ reduced bone mineral density formation, ${ }^{34}$ and white matter integrity of the brain. ${ }^{35}$ We have previously reported that ADAMTS18 is associated with platelet lyses and cerebral infarction in a postischemic stroke model ${ }^{36}$ To further study the role of ADAMTS18 in vivo, we developed an Adamts 18 knockout (KO) mouse strain. ${ }^{37}$ Our recent unpublished data (R.Z., N.Y., and W.Z.) showed that ADAMTS18 deficiency is associated with bone mass in mice. When measuring the bone mineral density by dual-energy X-ray absorptiometry, we unexpectedly found that Adamts $18 \mathrm{KO}$ mice exhibited significantly elevated body fat percentage compared with their wide-type (WT) littermates. This finding prompted a further search for a potential association between ADAMTS18 and adipogenesis. In this study, using Adamts 18 $\mathrm{KO}$ mice as an in vivo model, we investigated the role of ADAMTS18 in fat metabolism and associated disorders in mice.

\section{Materials and Methods}

\section{Reagents}

All reagents were from Sigma-Aldrich (St. Louis, MO) unless otherwise designed. Primary antibodies used in this study are listed in Table 1.

\section{Animals}

Adamts18 KO mice were generated as previously described. ${ }^{37}$ Littermates of Adamts $18 \mathrm{KO}$ and WT mice were obtained by mating between heterozygotes. Mice used in this study were on a mixed 129 Sv/C57BL6 background, were maintained under a 12-hour light/dark cycle, and were provided water and food ad libitum in a specific pathogen-free facility at East China Normal University (Shanghai, China). All procedures in animal experiments were approved by the Institutional Animal Care and Use Committee of East China Normal University. All methods were performed in accordance with the relevant guidelines and regulations.

\section{Hematoxylin and Eosin Staining and Cell Size Quantification}

Mice were sacrificed by cervical dislocation under narcosis. Adipose tissue samples were dissected and immediately fixed in $10 \%$ formaldehyde in phosphate-buffered saline, $\mathrm{pH}$ 7.4, dehydrated, embedded in paraffin, and divided into sections with a microtome. Standard hematoxylin and eosin staining was performed on paraffin sections (4 $\mu \mathrm{m}$ thick) of 
Table 2 Primers for Quantitative Real-Time RT-PCR

\begin{tabular}{lll}
\hline Gene & Primers & Length, bp \\
\hline Pparg & F: 5'-AGCCCTTTGGTGACTTTATGGA-3' & 171 \\
& R: 5'-GCAGCAGGTTGTCTTGGATGT-3' & \\
Cebpb & F: 5'-CGGGTTTCGGGACTTGATGC-3' & 133 \\
& R: 5'-TCAACAACCCCGCAGGAACAT-3' & \\
Fabp4 & F: 5'-GTGATGCCTTTGTGGGAACCT-3' 234 \\
& R: 5'-TCCTGTCGTCTGCGGTGATT-3' & \\
Acsl4 & F: 5'-TCAAGAAGGGAAGCAAGGGTG-3' & 199 \\
& R: 5'-TTACAAAGAGGGGCGTCATAGC-3' & \\
Adamts16 F: 5'-GCAACCCCAAGACACGACCT-3' & 90 \\
& R: 5'-ACACGCTCCAGTTTCCCACA-3' & \\
Actb & F: 5'-CCACCATGTACCCAGGCATT-3' & 253 \\
& R: 5'-AGGGTGTAAAACGCAGCTCA-3' & \\
& &
\end{tabular}

F, forward; R, reverse.

adipose tissues. Single adipocyte size $\left(\mu \mathrm{m}^{2} ; \times 200\right)$ was measured using ImageJ software version $1.50 \mathrm{i}(\mathrm{NIH}$, Bethesda, MD; http://imagej.nih.gov/ij).

\section{Western Blotting}

Adipose tissue samples were collected and lysed with radioimmunoprecipitation assay buffer $(20 \mathrm{mmol} / \mathrm{L}$ tris, 2.5 mmol/L EDTA, $1 \%$ Triton X-100, $1 \%$ deoxycholate, $0.1 \%$ SDS, $40 \mathrm{mmol} / \mathrm{L} \mathrm{NaF}, 10 \mathrm{mmol} / \mathrm{L} \mathrm{Na}_{4} \mathrm{P}_{2} \mathrm{O}_{7}$, and $1 \mathrm{mmol} / \mathrm{L}$ phenylmethylsulfonyl fluoride) supplemented with proteinase inhibitor cocktail (Calbiochem, San Diego, CA). Total protein concentration was determined using a Micro BCA Protein Assay kit (Pierce, Rockford, IL). Proteins were separated on $8 \%$ to $12 \%$ SDS-PAGE and immunoblotted with specific primary antibodies listed in Table 1, followed by species-appropriate horseradish peroxidase-coupled secondary antibody for 1 hour at room temperature. Proteins were visualized with an enhanced chemiluminescence kit (Millipore, Boston, MA), according to the manufacturer's instructions, and quantified using ImageJ version 1.50i.

\section{RT-PCR}

Total RNA was isolated from the vWAT, s.c. (inguinal) adipose tissue, and brown adipose tissue of mice using TRNzol-A ${ }^{+}$ Reagent (TIANGEN, Beijing, China). Total RNA was reverse transcribed to cDNA using a FastQuant RT kit (with gDNase) (TIANGEN), according to the manufacturer's instructions. An Adamts 18 cDNA fragment was amplified with primers specific to Adamts 18 exons 4 and 6. The primer sequences were as follows: exon 4 forward, 5'-TCCTCATCTCACCGCTACCTCA-3'; and exon 6 reverse, 5'-GGTCCCATCTTTGAACAGGCTA- $3^{\prime}$. A $\beta$-actin cDNA fragment was amplified as an internal control using the following primers: $5^{\prime}$-CCACCATGTACCCAGGCATT-3' (forward) and $5^{\prime}$-AGGGTGTAAAACGCAGCTCA-3' (reverse).

\section{Quantitative Real-Time RT-PCR Analysis}

Total RNA was isolated and transcribed, as described in $R T$-PCR. The quantitative real-time RT-PCR was performed using a StepOnePlus real-time PCR system (ThermoFisher, Carlsbad, CA) with SuperReal PreMix Plus (SYBR Green; TIANGEN), according to the manufacturer's instructions. Primers used in quantitative real-time RT-PCR are listed in Table 2 . The relative quantity of target mRNA was analyzed using the $\Delta \Delta \mathrm{Ct}$ method, with Actb as a reference gene. All reactions were performed as biological triplicates.

\section{Isolation of Adipocytes and SVF Cells}

Adipocytes and SVF cells were isolated from the vWAT of Adamts $18 \mathrm{KO}$ mice and WT littermates at 3 to 4 weeks of age, as described. ${ }^{38}$ Briefly, vWAT was harvested from mice, washed, and digested in $1.5 \mathrm{~g} / \mathrm{L}$ collagenase type II solution containing $20 \mathrm{~g} / \mathrm{L}$ bovine serum albumin and $1.2 \mathrm{~g} / \mathrm{L}$ HEPES for 1 hour, with constant shaking at $37^{\circ} \mathrm{C}$. Digestion was finished by adding the same volume of $0.01 \mathrm{~mol} / \mathrm{L}$ phosphatebuffered saline, followed by a filtration using a $0.22-\mu \mathrm{m}$ filter to remove undigested tissue. After centrifugation at $1000 \times g$ for 10 minutes, floating adipocytes were collected in a fresh tube. SVF cells from the precipitate were resuspended in Dulbecco's modified Eagle's medium supplemented with $10 \%$ fetal bovine serum and $1 \%$ penicillin/streptomycin.

\section{Cell Culture and Induction of Adipogenic Differentiation}

SVF cells were seeded equivalently in laminin-coated $(10 \mu \mathrm{g} / \mathrm{mL})$ or uncoated plates and cultured in Dulbecco's modified Eagle's medium supplemented with $10 \%$ fetal bovine serum and $1 \%$ penicillin/streptomycin at $37^{\circ} \mathrm{C}$ with $5 \% \mathrm{CO}_{2}$. Cells were seeded at a low density and allowed to grow until the following day, when the cell density reached $20 \%$ to $30 \%$ confluence. The cells were treated with induction medium [0.5 $\mathrm{mmol} / \mathrm{L}$ isobutyl-methyl-xanthine, $1 \mu \mathrm{mol} / \mathrm{L}$ dexamethasone, and $10 \mu \mathrm{g} / \mathrm{mL}$ insulin (INS)] for 2 days to induce adipogenic differentiation. Then, cells were cultured in Dulbecco's modified Eagle's medium supplemented with $10 \%$ fetal bovine serum and $10 \mu \mathrm{g} / \mathrm{mL}$ INS for another 2 days until they were prepared for oil red $\mathrm{O}$ staining.

\section{Oil Red 0 Staining of Cultured Cells}

Oil red $\mathrm{O}$ staining was performed according to the standard protocols. ${ }^{39}$ Briefly, cells were washed with phosphatebuffered saline three times and fixed with $3.7 \%$ formaldehyde for 15 minutes. Oil red $\mathrm{O}$ ( $0.5 \%$ in isopropanol) was filtered through a $0.22-\mu \mathrm{m}$ filter and incubated with cells for 
A

B
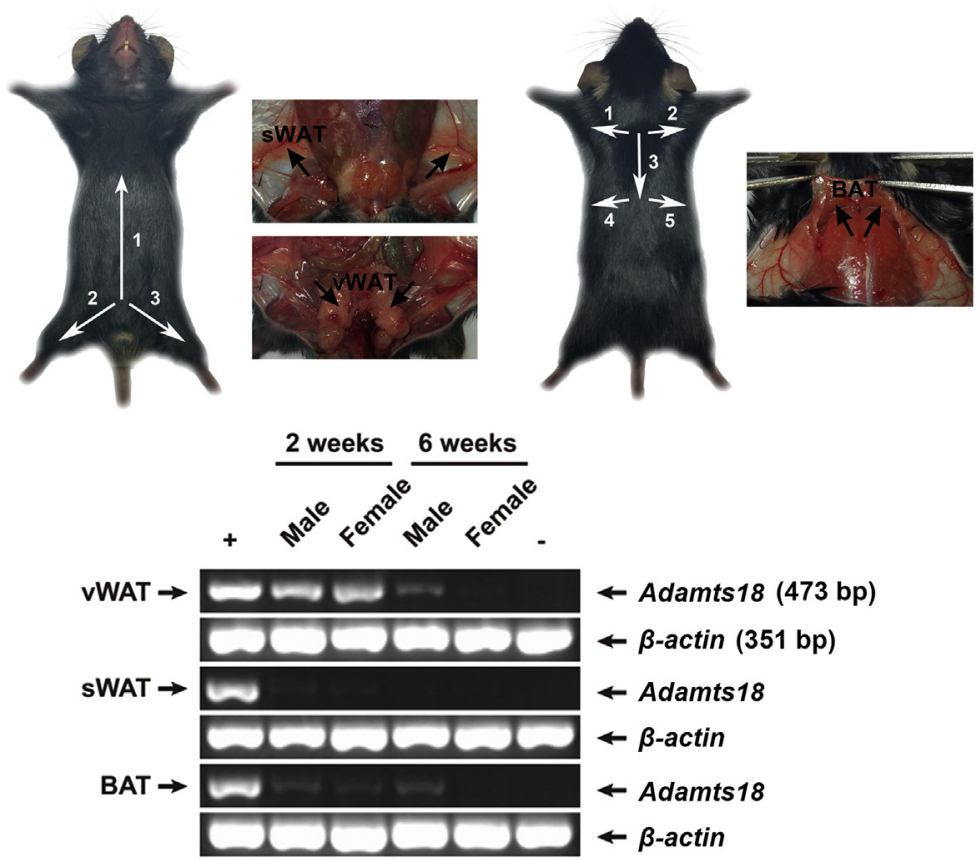

C

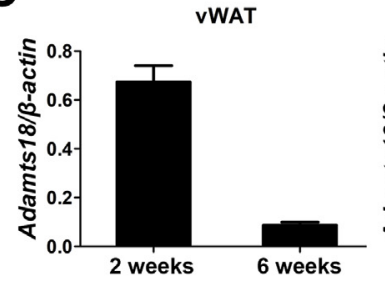

SWAT

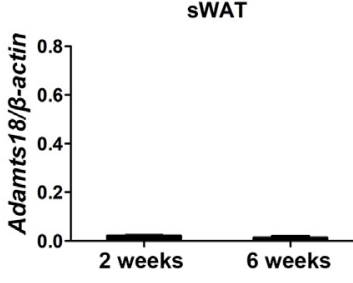

BAT

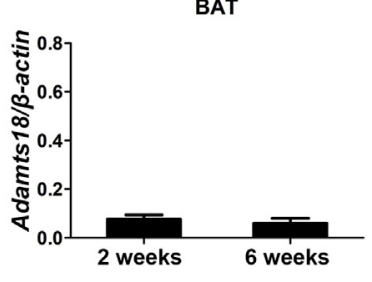

Figure 1 Expression of Adamts18 in mouse adipose tissues. A: Anatomical positions of visceral (gonadal) white adipose tissue (VWAT), s.c. WAT (sWAT), and brown adipose tissue (BAT) in mice with a C57BL/6/129 Sv background. WAT samples were harvested through making incisions through mouse abdominal skin, according to the sequence of numbers. Left panels: White arrows indicate the direction of incision. Black arrows point to the location of sWAT and vWAT. Right panels: BAT samples were harvested through making incisions through the mouse back skin, according to the sequence of numbers. White arrows indicate the direction of incision. The numbers represent the order in which the incisions were made. Black arrows point to the location of BAT. B and C: Adamts18 mRNA expression profile in vWAT, sWAT, and BAT from both male and female wild-type (WT) mice at 2 and 6 weeks after birth, respectively. Adamts 18 mRNA expression levels in brain of WT and knockout (KO) mice were used as positive $(+)$ and negative $(-)$ control, respectively (B). Densitometric quantification normalized to $\beta$-actin was calculated to assess the expression change of Adamts 18 mRNA, and three animals per sex were pooled and analyzed (C). These experiments were repeated independently at least three times (C). Data are expressed as means \pm SEM (C).
1 hour at room temperature. Cells were then washed with water, and the stained lipid droplets in adipocytes were visualized and imaged by a microscope. The positively stained adipocytes were quantified under the microscope.

\section{Apoe ${ }^{-/-} /$Adamts $18^{-/-}$Mouse Models for Atherosclerosis}

Apoe knockout (Apoe ${ }^{-/-}$) mice (C57/BL6; JunKe Co, Ltd, Nanjing, China) and Adamts $18^{-/-}$mice (C57/BL6/129 Sv) were crossbred to generate Apoe $e^{+/-} /$Adamts $18^{+/-}$mice, which were used to obtain Apoe $e^{-/-} /$Adamts $18^{+/+}$and Apoe ${ }^{-/-} /$Adamts18 knockout (Adamts18 ${ }^{-/}$) littermates. Atherosclerosis was induced by feeding male mice at 8 weeks of age a high-fat diet containing $1.25 \%$ cholesterol (Research Diet; JunKe Co, Ltd) for 12 weeks. Blood was collected by heart puncture for measurement of serum lipids, including TG, low-density lipoprotein (LDL), highdensity lipoprotein (HDL), and total cholesterol (TC), with kits. To assess lesions, heart-aorta complexes were excised, followed by thoracic-abdominal aortas (TAs) fixed with $10 \%$ formalin. Aortic sinuses and arches were embedded with OCT for frozen section preparation.

\section{Oil Red 0 Staining of Artery}

Oil red $\mathrm{O}$ staining was used to assess the size of the atherosclerotic lesion and its lipid content. Briefly, TAs were dissected, and en face oil red $\mathrm{O}$ staining of the artery plaque area was performed. Cross sections of aortic sinuses were fixed with $10 \%$ formalin, dehydrated with propylene glycol, and stained with $0.5 \%$ oil red O. For quantification, ImageJ version $1.50 \mathrm{i}$ was used to measure the lesion size of TAs and intimal areas of aortic sinuses. Lipid deposition was expressed as the percentage of oil red $\mathrm{O}-$ positive area in TA and the intima of sinuses.

\section{Sandwich ELISA}

For the sandwich enzyme-linked immunosorbent assay (ELISA) analysis, LDL (mouse LDL ELISA kit), HDL (mouse HDL ELISA kit), TG (mouse TG ELISA kit), TC (mouse TC ELISA kit), leptin (LEP; mouse LEP ELISA kit), INS (mouse INS ELISA kit), INS receptor (mouse INS receptor ELISA kit), GLU (mouse GLU ELISA kit), laminin (LN; mouse LN ELISA kit), thrombospondin 1 (THBS1; mouse THBS1 ELISA kit), Col IV (mouse Col type IV 
A

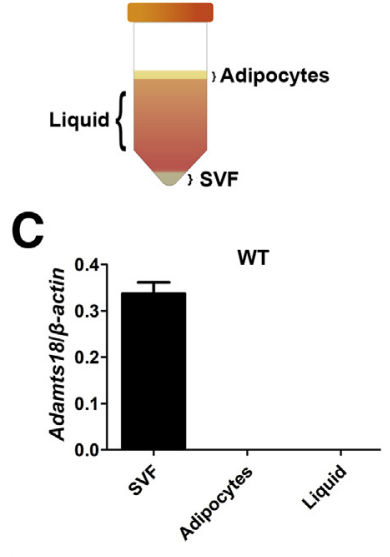

$\mathbf{F}$

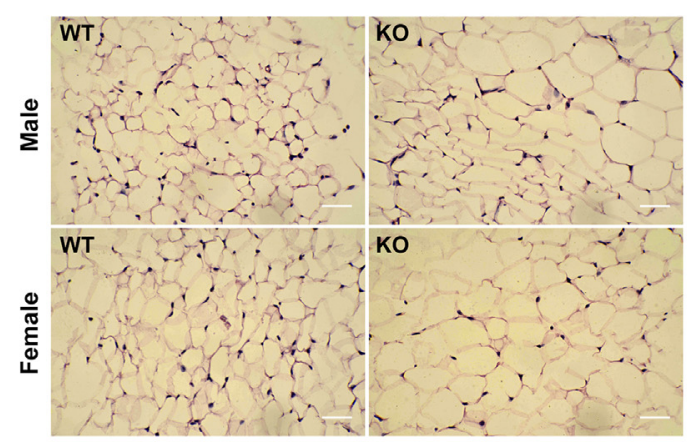

B

D
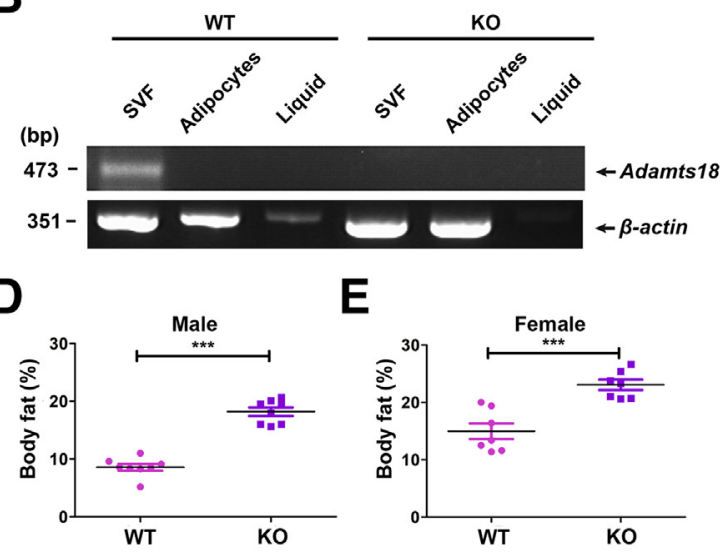

E

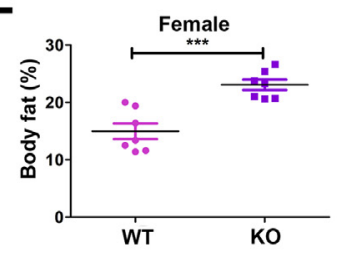

G

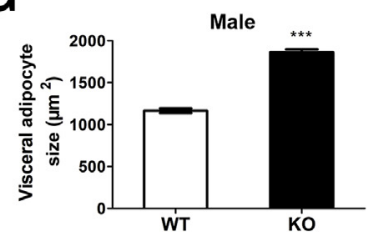

H

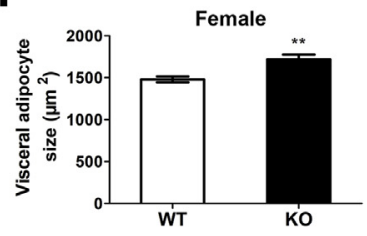

Figure 2 Increased visceral (gonadal) white adipose tissue (VWAT) in Adamts18 knockout (KO) mice. A: Cartoon depicting the method of isolating different fractions within the vWAT. B and C: RTPCR analysis of expression of Adamts 18 mRNA in different fractions of vWAT of wild-type (WT) mice and Adamts 18 K0 mice. $\beta$-actin was used as an internal reference. $\mathbf{D}$ and $\mathbf{E}$ : Body fat composition analysis. Body fat composition analysis by dualenergy $\mathrm{X}$-ray absorptiometry in different genotype of male (D) and female (E) mice, aged 8 to 10 weeks. F: Representative hematoxylin and eosin staining of vWAT in different genotype of mice. $\mathbf{G}$ and H: Quantification of vWAT adipocyte size. Single adipocyte size was measured using ImageJ version 1.50i. Average adipocyte size of each mouse was calculated from approximately 270 adipocytes (three random fields of each section were selected, and three replicate sections from each mouse were analyzed). There were at least three individual sex-matched mice in each group (C, G, and $\mathbf{H})$. Results are expressed as means $\pm \operatorname{SEM}(\mathbf{C}, \mathbf{D}, \mathbf{E}, \mathbf{G}$, and $\mathbf{H}) . n=3$ per group (B and $\mathbf{C}$ ); $n=8$ per group ( $\mathbf{D}$ and $\mathbf{E}$, male mice); $n=7$ per group (D and $\mathbf{E}$, female mice). ${ }^{* * P}<0.01,{ }^{* * * P}<0.001$ versus WT. Scale bars $=50 \mu \mathrm{m}(\mathbf{F})$. Original magnification, $\times 200$ (F). SVF, stromal vascular fraction.
ELISA kit), and Col VI (mouse Col type VI ELISA kit) were measured, according to the manufacturer's instructions of the ELISA kits (LYBD Bio-Technique Co, Ltd, Beijing, China).

\section{IPGTT and IPIST}

Adamts $18 \mathrm{KO}$ mice and WT littermates, at 8 to 10 weeks of age, were used for i.p. GLU tolerance test (IPGTT) and i.p. INS sensitivity test (IPIST). For IPGTT, mice were fasted overnight and then injected with GLU with $2 \mathrm{~g} / \mathrm{kg}$ body weight. Blood GLU levels were measured by automatic GLU monitor from the tail blood before injection and 60 and 120 minutes after injection. For IPIST, mice were fasted 4 hours and injected with INS at $0.75 \mathrm{U} / \mathrm{kg}$. Blood GLU levels were measured, as described earlier in this paragraph, immediately before injection and at 15, 30, 45, 60, and 120 minutes after injection.

\section{Blood Pressure Determination}

Mouse blood pressure was determined using an indirect tail cuff method with a Softron BP-98A indirect blood pressure meter (Softron Co Ltd, Tokyo, Japan). Adamts $18 \mathrm{KO}$ mice and WT littermates, at 8 weeks of age, were used for this measurement. Mouse blood pressure was determined between
1:00 PM and 4:00 PM, and repeated five times for each mouse after a 5 days' training period for habituation. The mean of five values was taken as the final blood pressure level.

\section{Statistical Analysis}

All data are expressed as means \pm SEM. Comparisons between two groups were made using unpaired $t$-tests. For IPGTT and IPIST study, two-way analyses of variance were used, followed by Bonferroni post hoc analysis when appropriate.

\section{Results}

\section{Expression of Adamts18 in Mouse Adipose Tissues}

To determine whether ADAMTS18 is associated with adipogenesis, its expression profile was first examined in different types of fat and different stages of fat development (Figure 1, A and B). RT-PCR analysis demonstrated that Adamts 18 mRNA was abundantly expressed in vWAT at a postnatal age of 2 weeks in both male and female mice, whereas its expression decreased dramatically (approximately sixfold decrease) in vWAT of mice at 6 weeks after birth (Figure 1, B and C). Adamts18 mRNA was almost 
A

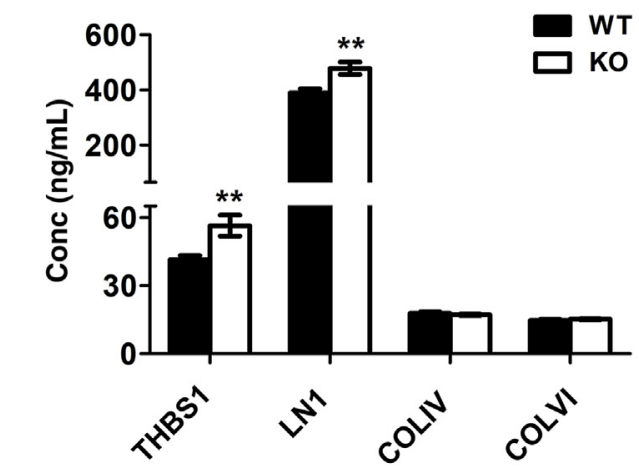

C

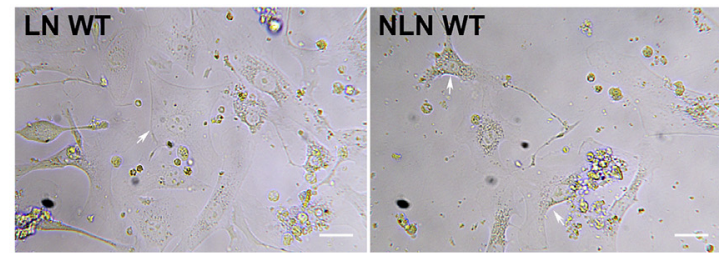

B
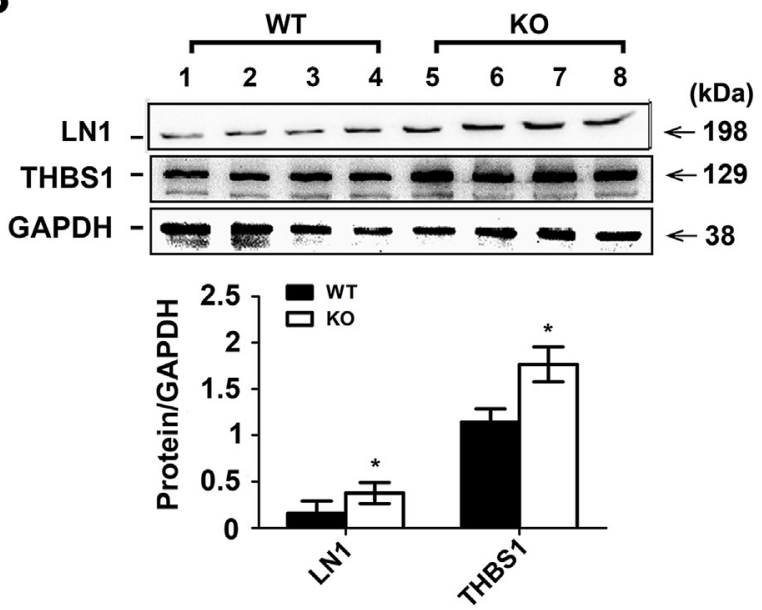

D
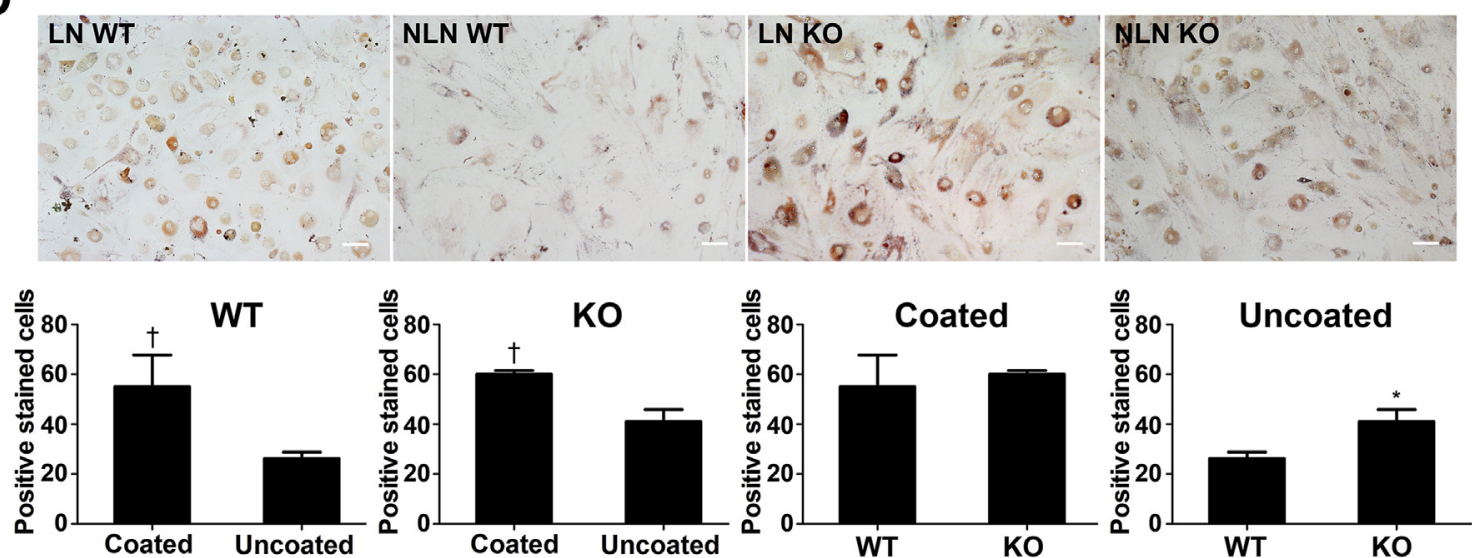

Figure 3 Altered extracellular matrix compositions in visceral (gonadal) white adipose tissue (vWAT) of Adamts18 knockout (K0) mice. A: Sandwich enzyme-linked immunosorbent assay analysis of levels of thrombospondin 1 (THBS1), laminin 1 (LN1), type IV collagen (COL), and type VI COL in vWAT tissues of 8- to 10-week-old wild-type (WT) and Adamts18 K0 male mice. B: Expression levels of LN1 and THBS1 determined by Western blotting and quantification of relative expression level of the proteins. C: The representative images of LN-coated and uncoated (NLN) substrata on the spreading of stromal vascular fraction cells separated from the vWAT of 3-week-old mice. D: Top row: Postconfluent cells in both LN-coated and NLN dishes were induced to differentiate; adipocyte was assessed by oil red 0 staining at day 4. Bottom row: Quantification of relative positive stained cells by oil red 0 staining in both LN-coated and NLN dishes. Data are expressed as means \pm SEM. $n=8$ per group (A); $n=4$ per group (B). ${ }^{*} P<0.05,{ }^{* *} P<0.01$ versus WT; ${ }^{\dagger} P<0.05$ versus uncoated. Scale bars $=100 \mu \mathrm{m}$ (C and D). GAPDH, glyceraldehyde-3-phosphate dehydrogenase.

undetectable in s.c. (inguinal) adipose tissue and brown adipose tissue at both 2 and 6 weeks after birth (Figure 1, B and $\mathrm{C}$ ). The expression of Adamts 18 mRNA was then examined in different fractions of the vWAT (Figure 2A). The results showed that Adamts 18 was mostly expressed in SVF cells in vWAT (Figure 2, B and C). Body composition analysis by dual-energy $\mathrm{X}$-ray absorptiometry revealed significantly elevated body fat percentage in adult Adamts 18 KO mice, aged 8 to 10 weeks, relative to WT littermates $(P<0.001)$ (Figure 2, D and E). Histopathological examinations showed that the size of adipocytes and lipid droplets in vWAT of Adamts $18 \mathrm{KO}$ mice was obviously larger than that in WT controls (Figure 2, F-H), whereas no apparent morphologic differences were observed in s.c. (inguinal) adipose tissue and brown adipose tissue (data not shown). The expression of uncoupling protein-1 was also examined in vWAT. RT-PCR analysis showed that the expression of uncoupling protein-1 mRNA in vWAT of Adamts $18 \mathrm{KO}$ mice was not significantly different from that in WT mice (Supplemental Figure S1). These results suggest that ADAMTS18 exerts an important influence on the early adipocyte directional differentiation of vWAT. 
A
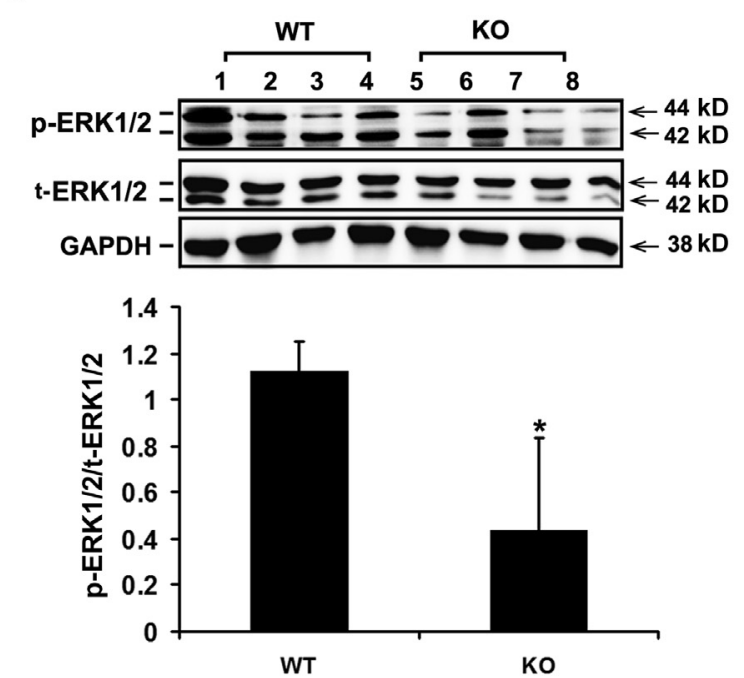

B
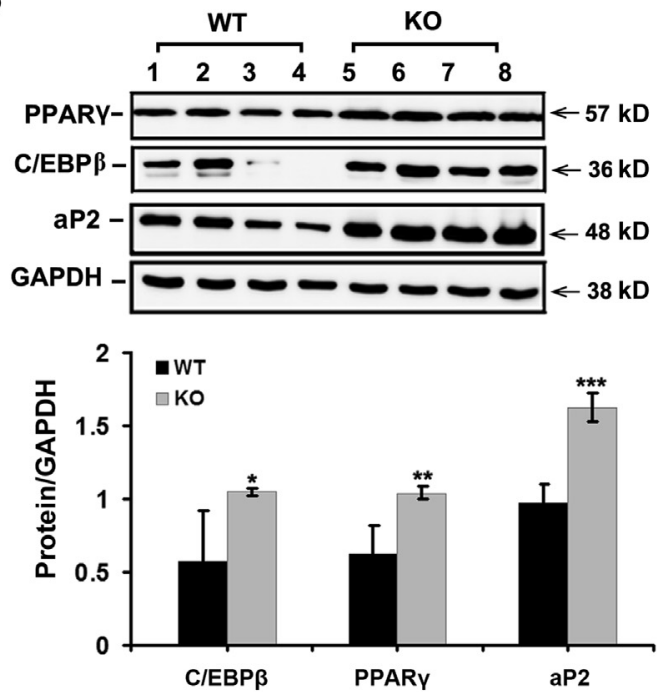

C

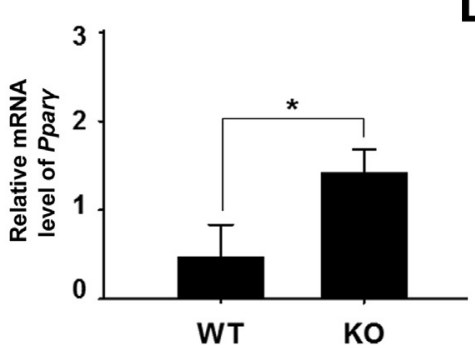

D

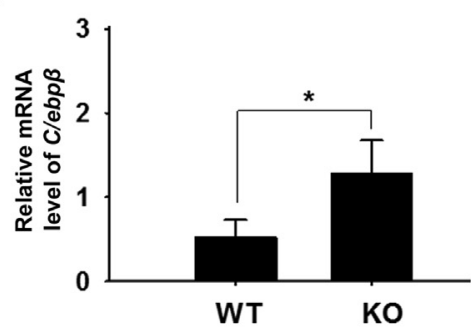

$\mathbf{E}$

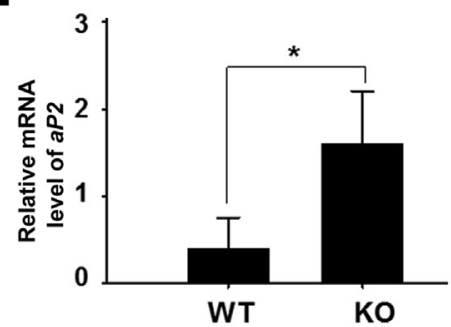

Figure 4 ADAMTS18 deficiency promotes visceral (gonadal) white adipose tissue (vWAT) differentiation by inhibition of the extracellular signal-regulated kinase 1 and 2 (ERK1/2) signaling pathway in mice. A: Top panel: Western blot analysis of the protein levels of total ERK1/2 (t-ERK1/2) and phosphorylated ERK1/2 (p-ERK1/2) in vWAT from age- and sex-matched mice with different genotypes. Bottom panel: Glyceraldehyde-3-phosphate dehydrogenase (GAPDH) was used as a loading control; the activity of ERK1/2 was expressed as the ratio of p-ERK1/2/t-ERK1/2. B: Top panel: Western blot analysis of the protein levels of peroxisome proliferator-activated receptor- $\gamma$ (PPAR $\gamma$ ), CCAAT/enhancer binding protein $\beta$ (C/EBP $\beta$ ), and adipocyte protein 2 (aP2) in vWAT from ageand sex-matched mice with different genotypes with the indicated antibodies. Bottom panel: Relative expression levels of the proteins are represented as protein/GAPDH. C-E: The relative mRNA expression of Ppar $\gamma(\mathbf{C})$, C/ebp $\beta$ (D), and aP2 (E) in mouse vWAT determined by quantitative real-time RT-PCR. The relative quantity of target gene was normalized to housekeeping gene $\beta$-actin using the $\Delta \Delta C$ t method. Data are expressed as means \pm SEM $(\mathbf{A}-\mathbf{E}) . n=4$ (A-E). ${ }^{*} P<0.05,{ }^{*}{ }^{*} P<0.01$, and ${ }^{* *}{ }^{*} P<0.001$ versus WT (t-test). K0, knockout; WT, wild type.

\section{ADAMTS18 Deficiency Alters ECM Composition in vWAT, which Promotes Adipocyte Differentiation}

The ECM microenvironment plays important roles in adipocyte development and expansion and in the phenotypic fate of mesenchymal stem cells. ${ }^{4,5}$ To clarify whether enlarged vWAT in Adamts $18 \mathrm{KO}$ mice is related to ECM remodeling, the key adipogenesis-related ECM proteins were examined. A sandwich ELISA showed that the protein levels of LN1 and THBS1 were significantly increased in vWAT tissue of Adamts $18 \mathrm{KO}$ mice compared with those in WT controls; however, the protein levels of Col IV and VI showed no significant differences between Adamts $18 \mathrm{KO}$ mice and WT controls (Figure 3A). Western blotting analysis further confirmed that both LN1 and THBS1 were increased in vWAT of Adamts18 KO mice compared with those of WT controls (Figure 3B). In vitro, SVF cells separated from the $\mathrm{vWAT}$ of mice were respectively seeded in LN-coated and uncoated culture dishes and treated with a standard adipocyte differentiation protocol. Markedly enhanced preadipocyte spreading (from both WT and Adamts18 $\mathrm{KO}$ mice) was observed in $\mathrm{LN}$-coated dishes relative to uncoated dishes (Figure 3C). After 6 days of differentiation induction, the number of cells stained by oil red $\mathrm{O}$ in LN-coated dishes (from both WT and Adamts 18 KO mice) was obviously more than that in LN-uncoated dishes (Figure 3D). Furthermore, oil red $\mathrm{O}-$ stained cells, originated from SVF cells of Adamts $18 \mathrm{KO}$ mice, were obviously more than those from WT mice in LN-uncoated dishes (Figure 3D). These results suggest that enlarged vWAT in Adamts18 KO mice may be attributed, in part, to ECM remodeling, especially increased LN expression.

\section{ADAMTS18 Deficiency Promotes vWAT Differentiation through Inhibition of the ERK1/2 Pathway in Mice}

It is well known that ECM components critically regulate adipocyte differentiation by affecting ERK1/2 pathways and 
A

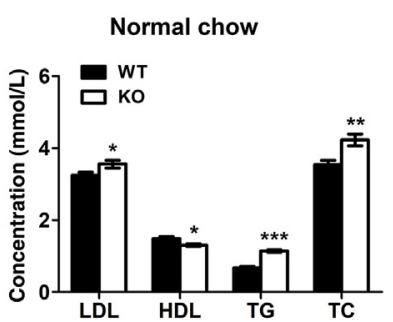

D
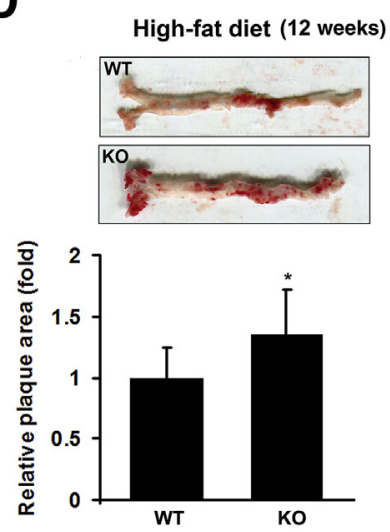

B

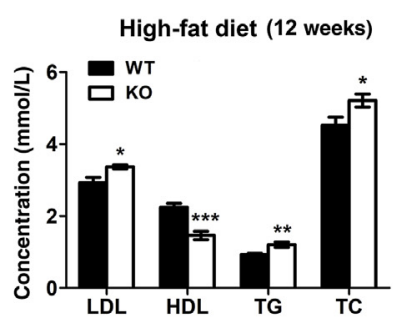

E
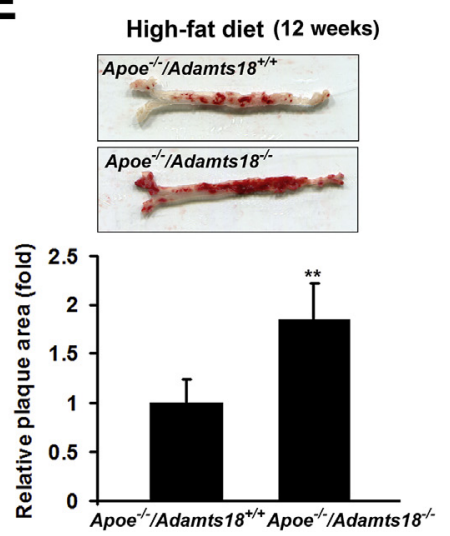

C

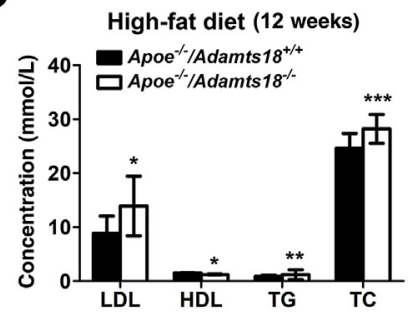

$\mathbf{F}$
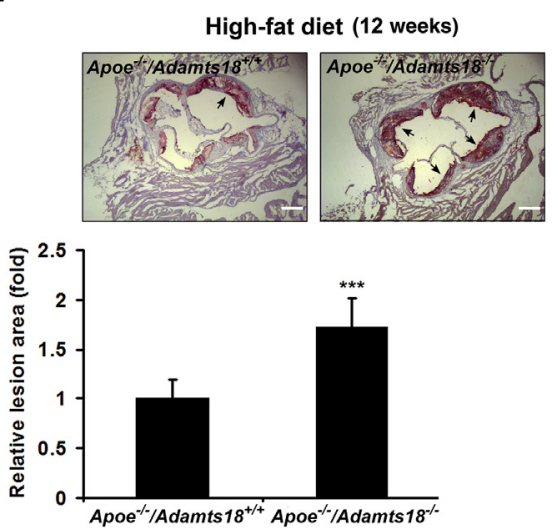

Figure 5 ADAMTS18 deficiency promotes atherosclerosis in Apoe ${ }^{-/-}$mice. A and B: Serum lipid levels in 8-week-old wild-type (WT) and Adamts18 knockout (KO) males with a normal chow diet (A) or after a high-fat diet (HFD) for 12 weeks (B). C: Serum lipid levels in Apoe ${ }^{-1-}$ male mice with different genotypes of Adamts18. D-F: 0il red 0 staining of artery plaque area in the thoracic-abdominal aorta (TA). En face oil red 0 staining of artery plaque area in TA of WT and Adamts18 K0 mice (D) or in TA of Apoe ${ }^{-/-} /$Adamts $18^{+/+}$and Apoe $e^{-/} /$Adamts $18^{-/-}$mice (E) or oil red 0 staining of lesion size in the aortic sinus of $A$ poe $e^{-/-} /$Adamts $18^{+/+}$and Apoe $e^{-/-} /$Adamts $18^{-/-}$mice $(\mathbf{F})$ after an HFD for 12 weeks. D-F: Top panels: Representative images of oil red 0 staining. Bottom panels: For quantification, ImageJ version 1.50i was used to measure the plaque area or lesion size of TA of aortic sinuses. Arrows in $\mathbf{F}$ indicate the location of Oil red 0 staining of lesion size in the aortic sinus of Apoe $e^{-/-} /$Adamts $18^{+/+}$and $A p o e^{-/-} /$Adamts $18^{-/-}$mice. Data are expressed as means \pm SEM $(\mathbf{A}-\mathbf{F}) . n=7$ per group $(\mathbf{A}) ; n=6$ per group $(\mathbf{B}$ and $\mathbf{D}) ; n=10$ to 11 per group $(\mathbf{C}) ; n=5$ per group $(\mathbf{E}$ and $\mathbf{F}) .{ }^{*} P<0.05,{ }^{*} P<0.01$, and ${ }^{* * *} P<0.001$ versus control. Scale bars $=200 \mu \mathrm{m}(\mathbf{F})$. HDL, high-density lipoprotein; LDL, low-density lipoprotein; TC, total cholesterol; TG, triglyceride.

the downstream adipocyte-specific signaling pathway. 40 ADAMTS18 deficiency significantly decreased the level of phosphorylated ERK1/2 in vWAT (Figure 4A). Consistently, the protein levels of adipogenic transcription factors, including peroxisome proliferator-activated receptor- $\gamma$, CCAAT/enhancer binding protein $\beta$, and adipocyte-specific marker adipocyte protein 2 , were significantly increased in vWAT of Adamts18 $\mathrm{KO}$ mice relative to WT controls (Figure 4B). The expression of these adipogenic factors was also checked at the mRNA level by quantitative real-time RT-PCR, and similar results were shown (Figure 4, C-E). However, ADAMTS18 deficiency did not affect the protein level of total and phosphorylated p38 mitogen-activated protein kinase (data not shown). In addition, expression of acyl-CoA synthetase long-chain family member 4, which plays a crucial role in lipolysis, showed no significant difference between Adamts18 KO mice and WT littermates (Supplemental Table S1).

\section{ADAMTS18 Deficiency Causes Increased Serum Lipid Levels in Mice}

Increased visceral fat volume is a major contributory factor in hyperlipidemia, because excessive TG is continually released by fat cells into the bloodstream. ${ }^{1,2}$ To further investigate the relevance of ADAMTS18 and hyperlipidemia, the blood lipid level of mice was examined. Compared with WT controls, Adamts $18 \mathrm{KO}$ mice fed a regular chow diet showed increased $\mathrm{LDL}$ (KO versus WT, $3.56 \pm 0.28$ versus $3.25 \pm 0.22 \mathrm{mmol} / \mathrm{L}$; $P=0.0408$ ), decreased HDL (KO versus WT, $1.30 \pm 0.09$ versus $1.48 \pm 0.15 \mathrm{mmol} / \mathrm{L} ; P=0.018)$, increased TG $(\mathrm{KO}$ versus WT, $1.31 \pm 0.07$ versus $0.84 \pm 0.09 \mathrm{mmol} / \mathrm{L}$; $P<0.001$ ), and increased TC (KO versus WT, $4.79 \pm 0.43$ versus $4.1 \pm 0.33 \mathrm{mmol} / \mathrm{L} ; P=0.0058 ; n=7$ per group) (Figure 5A).

\section{ADAMTS18 Deficiency Promotes Atherosclerosis in Apoe $^{-/-}$Mice}

Because increased serum lipid level is a major risk factor for atherosclerosis, ${ }^{6,7}$ the effect of ADAMTS18 was further evaluated on atherosclerosis. After a high-fat diet for 12 weeks, Adamts $18 \mathrm{KO}$ mice displayed significantly increased LDL, TG, and TC and decreased HDL relative to WT littermates (Figure 5B). Similarly, Apoe $e^{-/-} /$Adamts $18^{-/-}$mice showed increased LDL, TG, and TC and decreased HDL relative to Apoe ${ }^{-/-} /$Adamts $18^{+/+}$littermates (Figure 5C). Oil red $\mathrm{O}$ staining showed that artery plaque area in TA of Adamts18 KO 


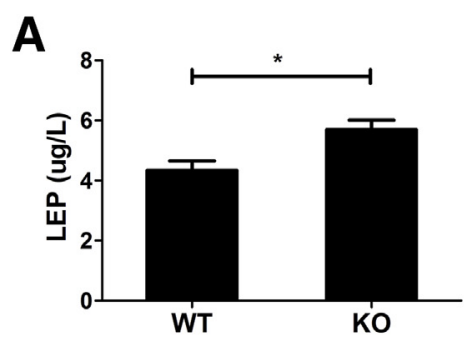

D

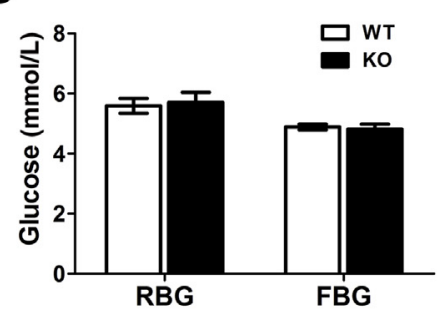

B

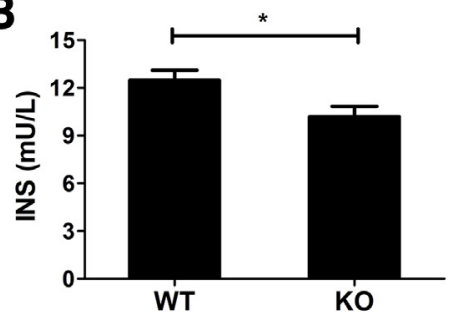

E

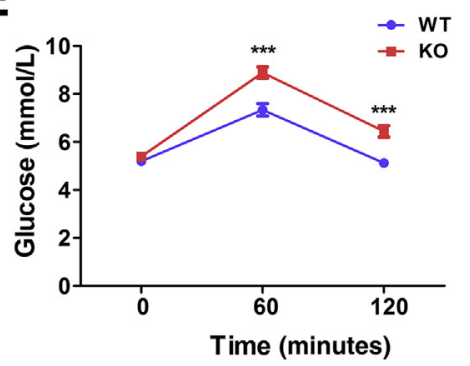

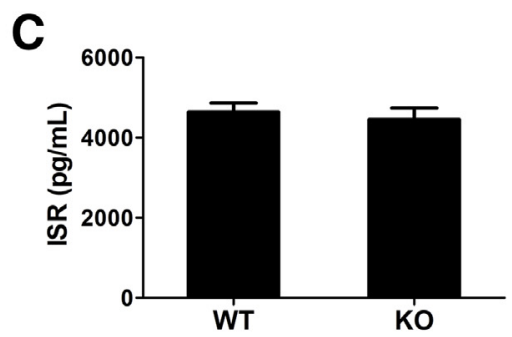

$\mathbf{F}$

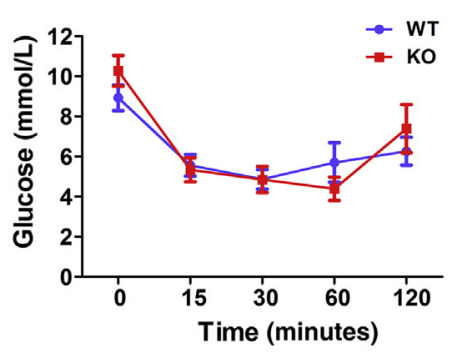

Figure 6 ADAMTS18 deficiency results in abnormal blood glucose regulation in mice. A-C: Levels of leptin (LEP; A), insulin (INS; B), and insulin receptor (ISR; C) in serum of 8- to 10-week-old male Adamts18 knockout (KO) mice and wild-type (WT) littermates measured by sandwich enzyme-linked immunosorbent assay. D: Random blood glucose (RBG) and fasting blood glucose (FBG) measured by glucometer in 8- to 10-week-old male Adamts18 K0 mice and WT littermates. E and F: Glucose concentrations measured by glucometer in 8- to 10-week-old male Adamts18 K0 mice and WT littermates during an i.p. glucose tolerance test (IPGTT; E) and an insulin sensitivity test (IPIST; F). Two-way analyses of variance were used for IPGTT and IPIST, followed by the Bonferroni post hoc analysis. Data are expressed as means \pm SEM $(\mathbf{A}-\mathbf{F}) . n=7$ per group $(\mathbf{A}-\mathbf{C}) ; n=6$ per group (D); $n=12(\mathbf{E}$ and $\mathbf{F}, \mathrm{KO}$ mice); $n=11$ (E and $\mathbf{F}$, WT mice). ${ }^{*} P<0.05, * * * P<0.001$.

mice was significantly increased by approximately 1.42 -fold in comparison to that of WT littermates (Figure 5D). Consistently, artery plaque area in TA of Apoe $e^{-/} /$Adamts $18^{-/-}$mice was significantly increased by approximately 1.85 -fold in comparison to that of Apoe $e^{-/} /$Adamts $18^{+/+}$littermates (Figure 5E). Moreover, Apoe $e^{-/} /$Adamts $18^{-/-}$mice showed a significantly increased lesion size by approximately 1.72 -fold in the aortic sinus compared with Apoe $e^{-/-} /$Adamts $18^{+/+}$littermates (Figure 5F).

\section{ADAMTS18 Deficiency Causes Abnormal Blood GLU Metabolism in Mice}

Visceral fat is an important endocrine organ. ${ }^{1,2}$ The results of sandwich ELISA demonstrated that Adamts18 KO mice showed significantly increased serum LEP level relative to WT littermates (KO versus WT, $5.69 \pm 0.78$ versus $4.33 \pm 0.77 \mu \mathrm{g} / \mathrm{L} ; P=0.01 ; n=7$ per group) (Figure $6 \mathrm{~A}$ ). Furthermore, Adamts $18 \mathrm{KO}$ mice showed a significantly decreased serum INS level relative to WT littermates (KO versus WT, $10.2 \pm 1.6$ versus $12.5 \pm 1.5 \mathrm{mU} / \mathrm{L} ; P=0.026$; $n=7$ per group) (Figure $6 \mathrm{~B}$ ). However, the concentration of INS receptor showed no significant difference between Adamts $18 \mathrm{KO}$ and WT mice (KO versus WT, $4555.6 \pm 621.8$ versus $4533.2 \pm 654.1 \mathrm{pg} / \mathrm{mL} ; P=0.95 ; n=7$ per group) (Figure 6C). There was no significant difference in fasting blood GLU and random blood GLU between Adamts $18 \mathrm{KO}$ and WT mice (Figure 6D). IPGTT demonstrated that Adamts $18 \mathrm{KO}$ mice showed higher blood GLU levels relative to WT controls at 60 and 120 minutes after i.p. GLU loading [GLU, KO versus WT, 60 minutes: $8.89 \pm 0.95$ versus
$7.34 \pm 0.83 \mathrm{mmol} / \mathrm{L}(P<0.001) ; 120$ minutes: $6.44 \pm 0.95$ versus $5.12 \pm 0.57 \mathrm{mmol} / \mathrm{L}(P<0.001)$ ] (Figure 6E). IPIST showed no significant differences in blood GLU levels between Adamts $18 \mathrm{KO}$ and WT mice at multiple time points after INS injection (Figure 6F), which suggests that there is no significant difference in INS sensitivity between Adamts18 $\mathrm{KO}$ and WT mice.

\section{ADAMTS18 Deficiency Causes Hypertension in Mice}

A blood pressure assay showed that both male and female Adamts $18 \mathrm{KO}$ mice showed higher blood pressure relative to WT littermates, and female mice showed this inclination more distinctively [male systolic pressure, KO versus WT, $124.17 \pm 22.97$ versus $110.33 \pm 8.52 \mathrm{mmHg}$; female systolic pressure, KO versus WT, $120.67 \pm 14.80$ versus $95.83 \pm 8.66$ mmHg $(P<0.01)$; male diastolic pressure, KO versus WT, $84.17 \pm 11.82$ versus $70.5 \pm 3.08 \mathrm{mmHg}(P<0.05)$; female diastolic pressure, $\mathrm{KO}$ versus WT, $85 \pm 12.66$ versus $69 \pm 7.72 \mathrm{mmHg}(P<0.05)$; male mean pressure, $\mathrm{KO}$ versus $\mathrm{WT}, 88.17 \pm 6.74$ versus $77.67 \pm 8.02 \mathrm{mmHg}(P<0.05)$; female mean blood pressure, $\mathrm{KO}$ versus WT, $88.17 \pm 6.74$ versus $77.67 \pm 8.02 \mathrm{mmHg}(P<0.05)]$ (Figure 7, A and B). Histological analysis showed that the thickness of the blood vessel wall in the common carotid artery of Adamts $18 \mathrm{KO}$ mice increased significantly (approximately 1.3 -fold) relative to WT littermates (Figure 7C).

\section{Discussion}

ADAMTS18 is an orphan ADAMTS whose pathophysiological roles remain unclear. In this study, we used 
A

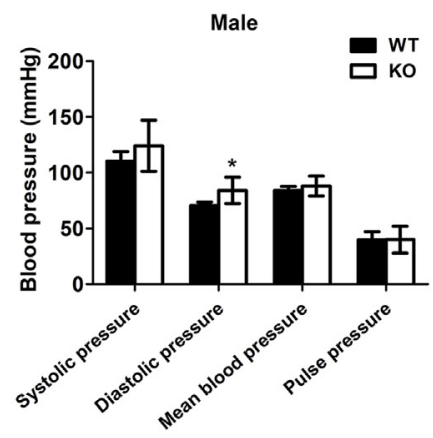

B

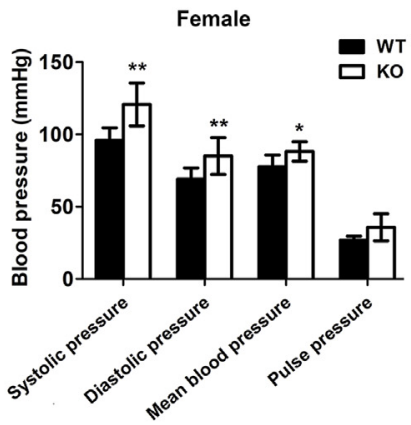

C

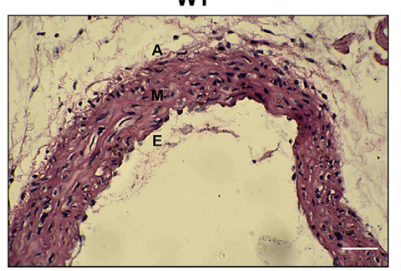

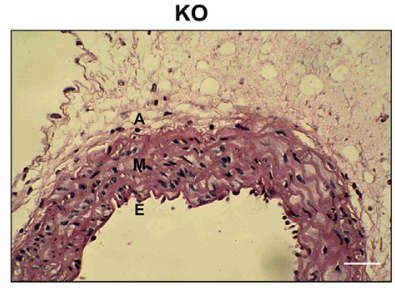

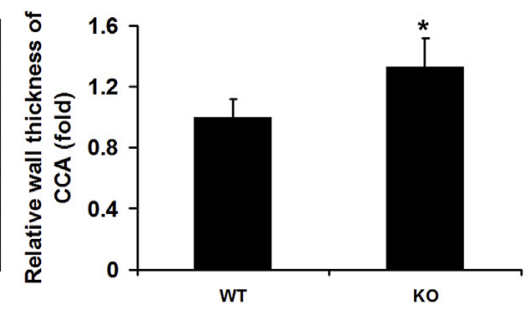

Figure 7 ADAMTS18 deficiency induces high blood pressure in mice. An indirect tail-cuff method was used to record the systolic blood pressure, diastolic blood pressure, and mean pressure. Pulse pressure refers to the difference between the systolic blood pressure and diastolic blood pressure. A and B: Blood pressure monitoring in 8-week-old male Adamts18 knockout (K0) mice and wild-type (WT) littermates (A) and female Adamts18 K0 mice and WT littermates (B). Each mouse was measured five times, and the mean of five values was taken as the final blood pressure level. C: Representative hematoxylin and eosin staining of common carotid artery (CCA) and the relative wall thickness of each group was analyzed. Data are expressed as means \pm SEM $(\mathbf{A}-\mathbf{C})$. $n=6(\mathbf{A}$ and B); $n=4$ (C). ${ }^{*} P<0.05,{ }^{*} P<0.01$ versus WT. Scale bars $=200 \mu \mathrm{m}$ (C). A, adventitia; E, endothelium; M, media.

Adamts $18 \mathrm{KO}$ mice as an in vivo model and demonstrated, for the first time, that ADAMTS18 deficiency promotes vWAT differentiation and leads to associated metabolic syndrome, including hyperlipidemia, abnormal blood GLU regulation, and hypertension, in mice. This study adds to the growing body of evidence that ADAMTSs are associated with adipogenesis and metabolic disorders. ${ }^{25-28}$

The ADAMTS family plays a pivotal role in organ development and various diseases because of its ECM remodeling activity. ${ }^{8-10}$ ECM composition and dynamics are of crucial importance to adipocyte function. ${ }^{3}$ ADAMTS18 deficiency increased LN1 and THBS1 in mouse vWAT
(Figure 3, A and B). LN is a major component of the basal lamina, and it plays an exclusive role in the morphologic aspects of preadipocyte development. It was reported that preadipocytes showed relatively higher affinity for LN1 than other ECM proteins, and this is conducive to preadipocyte adhesion, migration, and proliferation. ${ }^{41}$ Markedly enhanced preadipocyte spreading (Figure 3C) and an increased number of induced mature adipocytes were found in laminin-coated dishes relative to uncoated dishes (Figure 3D). This suggests that increased LN1 in vWAT of Adamts18 KO mice is a key factor for promoting adipocyte differentiation. THBS1 is an adipokine, and it is highly expressed in obese
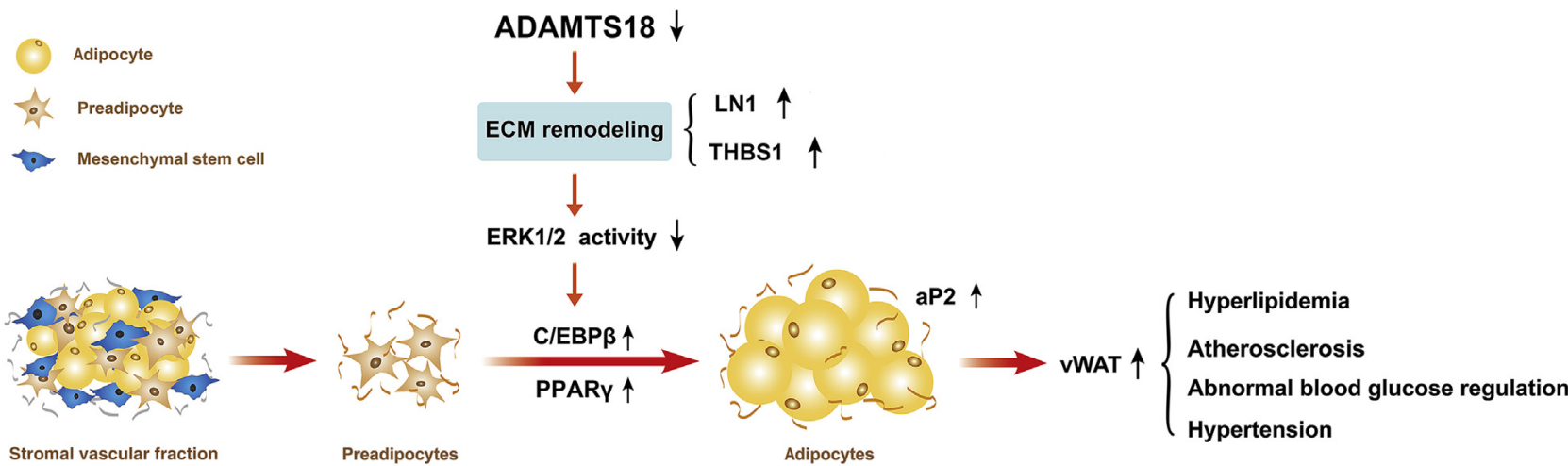

Figure 8 Schematic diagram of the role of Adamts18 in visceral (gonadal) white adipose tissue (vWAT) development and associated metabolic syndrome in mice. Adamts 18 was mostly expressed by stromal vascular fraction cells of vWAT. It exerts influence on the early adipocyte directional differentiation of vWAT through modulating extracellular matrix (ECM) remodeling. ADAMTS18 deficiency increases laminin 1 (LN1) and thrombospondin 1 (THBS1) expression, which inhibits extracellular signal-regulated kinase 1 and 2 (ERK1/2) activity and increases expression of adipogenic transcription factors peroxisome proliferatoractivated receptor- $\gamma$ (PPAR $\gamma$ ), CCAAT/enhancer binding protein $\beta$ (C/EBP $\beta$ ), and adipocyte-specific marker adipocyte protein 2 (aP2). Accordingly, it contributes to enlarged vWAT. Enlarged vWAT increases the risks of hyperlipidemia, atherosclerosis, blood glucose metabolic disorder, and hypertension in mice. 
individuals. ${ }^{42}$ Loss of THBS1 attenuated weight gain and fat accumulation in mice with a high-fat diet. ${ }^{43}$ The data that demonstrated increased THBS1 expression in enlarged vWAT tissue of Adamts $18 \mathrm{KO}$ mice are consistent with these reports. In addition, SVF cells separated from vWAT of Adamts $18 \mathrm{KO}$ mice were more prone to be induced to mature adipocytes than those from vWAT of WT mice (Figure 3D). These results suggest that enlarged vWAT in Adamts $18 \mathrm{KO}$ mice may be attributed, in part, to altered ECM composition, especially increased LN and THBS1 expression. ECM remodeling is a complex systematic process involving many molecules. Herein, the focus was on the regulation of $\mathrm{LN}$, THBS1, and Col during adipogenesis. However, other molecules, like secreted protein acidic and rich in cysteine, which functions as an inhibitor of adipogenesis, might also serve as a target for ADAMTS18 during adipocyte differentiation and lipid metabolism. Altogether, we propose that ADAMTS18 regulates adipogenesis by influencing the cell microenvironment through modifying ECM components rather than regulating a single target or substrate.

Adhesion to ECM regulates a variety of cellular processes, including proliferation, survival, and differentiation. ${ }^{44}$ Integrins are the main receptors that recognize fibronectin, laminin, and Col within the ECM. ${ }^{45}$ Engagement and clustering of integrins leads to intracellular signaling transduction. ${ }^{46}$ The ERK1/2 cascade is one of the most important pathways regulated by adhesion ${ }^{47}$ and is crucial for adipogenesis. ${ }^{48,49}$ ERK1/2 needs to be activated during early adipogenesis for normal clonal expansion, whereas phosphorylated ERK1/2 stimulates the phosphorylation of peroxisome proliferator-activated receptor- $\gamma$, which leads to the inhibition of adipogenesis in the later stage of adipocyte differentiation. Data showed that ERK1/2 activity was inhibited (Figure 4A), whereas the expression of its downstream adipocyte-specific transcription factors (peroxisome proliferator-activated receptor- $\gamma$, CCAAT/ enhancer binding protein $\beta$, and marker gene Fabp4) was increased, in vWAT of Adamts18 KO mice (Figure 4, $\mathrm{B}-\mathrm{E})$. Therefore, these findings suggest that ADAMTS18 regulates adipogenesis by affecting ERK1/2 activation through ECM remodeling.

ADAMTS18 deficiency led to hyperlipidemia in mice (Figure 5A). Hyperlipidemia is a major risk factor for atherosclerosis. ${ }^{50}$ Apoe $^{-1-}$ mouse has been used as an experimental model of atherosclerosis because it spontaneously develops hypercholesterolemia and atherosclerosis in a reproducible manner, similar to what is observed in humans. ${ }^{51}$ ADAMTS18 deficiency synergistically aggravated atherosclerosis in Apoe $e^{-1-}$ mice (Figure 5, B-F). In this regard, ADAMTS18 might be a potential clinical biomarker for screening of atherosclerotic patients.

This study also demonstrates that ADAMTS18 deficiency causes hypertension (Figure 7, A and B) and increased common carotid artery thickness (Figure $7 \mathrm{C}$ ) in mice. ADAMTS18 and ADAMTS16 form a phylogenetic clade. $^{52,53}$ The close evolutionary relationship between
ADAMTS18 and ADAMTS16 suggests that these proteins may also be functionally similar. Indeed, Adamts $16 \mathrm{KO}$ rats showed inherited hypotension because of increased $\mathrm{Col}$ in the aortic adventitia. ${ }^{54}$ However, a significant difference in the expression of Adamts 16 mRNA between Adamts $18 \mathrm{KO}$ mice and WT controls was not observed (Supplemental Table S2). We speculated that hypertension in Adamts 18 KO mice may be partly attributed to increased serum LEP level (Figure 6A). Several studies have shown that LEP may regulate blood pressure by exciting the sympathetic nervous system, ${ }^{55}$ lowering endothelial vasodilation function, ${ }^{56}$ and promoting the proliferation of vascular smooth muscle cells, thereby increasing peripheral vascular resistance. ${ }^{57}$

Adipose tissue distribution is a strong predictor of the occurrence of the metabolic syndrome in the context of obesity. ${ }^{6,7}$ Obese individuals who preferentially expand visceral adipose tissue are at a greater risk for diabetes and cardiovascular disease than are equally obese individuals who store excess energy in s.c. adipose tissue. ${ }^{6,7}$ To our knowledge, this is the first study that recognizes ADAMTS18 as a novel and important regulator of vWAT development and related metabolic syndrome by affecting ECM remodeling (Figure 8). In the future, ADAMTS18 might also be a target for the diagnosis and treatment of visceral adiposity and associated metabolic risks.

\section{Acknowledgments}

We thank Meng Liu and Zongying Nie for help with data analysis.

\section{Supplemental Data}

Supplemental material for this article can be found at https://doi.org/10.1016/j.ajpath.2017.10.020.

\section{References}

1. Kershaw EE, Flier JS: Adipose tissue as an endocrine organ. J Clin Endocrinol Metab 2004, 89:2548-2556

2. Buyse J, Decuypere E: Adipose tissue and lipid metabolism. Edited by Scanes CG. In Sturkie's Avian Physiology. ed 6. Oxford, UK: Elsevier, 2015. pp. 443-453

3. Mariman EC, Wang P: Adipocyte extracellular matrix composition, dynamics and role in obesity. Cell Mol Life Sci 2010, 67:1277-1292

4. Lijnen HR: Angiogenesis and obesity. Cardiovasc Res 2008, 78: 286-293

5. Nakajima I, Yamaguchi T, Ozutsumi K, Aso H: Adipose tissue extracellular matrix: newly organized by adipocytes during differentiation. Differentiation 1998, 63:193-200

6. Choi CHJ, Cohen P: Adipose crosstalk with other cell types in health and disease. Exp Cell Res 2017, 360:6-11

7. Klöting N, Blüher M: Adipocyte dysfunction, inflammation and metabolic syndrome. Rev Endocr Metab Disord 2014, 15:277-287

8. Apte SS: A disintegrin-like and metalloprotease (reprolysin-type) with thrombospondin type 1 motif (ADAMTS) superfamily: functions and mechanisms. J Biol Chem 2009, 284:31493-31497 
9. Kelwick R, Desanlis I, Wheeler GN, Edwards DR: The ADAMTS (a disintegrin and metalloproteinase with thrombospondin motifs) family. Genome Biol 2015, 16:113

10. Porter S, Clark IM, Kevorkian L, Edwards DR: The ADAMTS metalloproteinases. Biochem J 2005, 386:15-27

11. Colige A, Beschin A, Samyn B, Goebels Y, Van Beeumen J, Nusgens BV, Lapière CM: Characterization and partial amino acid sequencing of a $107-\mathrm{kDa}$ procollagen I N-proteinase purified by affinity chromatography on immobilized type XIV collagen. J Biol Chem 1995, 270:16724-16730

12. Colige A, Li SW, Sieron AL, Nusgens BV, Prockop DJ, Lapière CM: cDNA cloning and expression of bovine procollagen I N-proteinase: a new member of the superfamily of zinc-metalloproteinases with binding sites for cells and other matrix components. Proc Natl Acad Sci U S A 1997, 94:2374-2379

13. Colige A, Vandenberghe I, Thiry M, Lambert CA, Van Beeumen J, Li SW, Prockop DJ, Lapière CM, Nusgens BV: Cloning and characterization of ADAMTS-14, a novel ADAMTS displaying high homology with ADAMTS-2 and ADAMTS-3. J Biol Chem 2002, 277:5756-5766

14. Fernandes RJ, Hirohata S, Engle JM, Colige A, Cohn DH, Eyre DR, Apte SS: Procollagen II amino propeptide processing by ADAMTS3: insights on dermatosparaxis. J Biol Chem 2001, 276:31502-31509

15. Li SW, Arita M, Fertala A, Bao Y, Kopen GC, Långsjö TK, Hyttinen MM, Helminen HJ, Prockop DJ: Transgenic mice with inactive alleles for procollagen N-proteinase (ADAMTS-2) develop fragile skin and male sterility. Biochem J 2001, 355:271-278

16. Robker RL, Russell DL, Espey LL, Lydon JP, O’Malley BW, Richards JS: Progesterone-regulated genes in the ovulation process: ADAMTS-1 and cathepsin L proteases. Proc Natl Acad Sci U S A 2000, 97:4689-4694

17. Georgiadis KE, Hirohata S, Seldin MF, Apte SS: ADAM-TS8, a novel metalloprotease of the ADAM-TS family located on mouse chromosome 9 and human chromosome 11. Genomics 1999, 62:312-315

18. Clark ME, Kelner GS, Turbeville LA, Boyer A, Arden KC, Maki RA: ADAMTS9, a novel member of the ADAM-TS/metallospondin gene family. Genomics 2000, 67:343-350

19. Luan Y, Kong L, Howell DR, Ilalov K, Fajardo M, Bai XH, Di Cesare PE, Goldring MB, Abramson SB, Liu CJ: Inhibition of ADAMTS-7 and ADAMTS-12 degradation of cartilage oligomeric matrix protein by alpha-2-macroglobulin. Osteoarthritis Cartilage 2008, 16:1413-1420

20. Kuno K, Okada Y, Kawashima H, Nakamura H, Miyasaka M, Ohno H, Matsushima K: ADAMTS-1 cleaves a cartilage proteoglycan, aggrecan. FEBS Lett 2000, 478:241-245

21. Tortorella MD, Burn TC, Pratta MA, Abbaszade I, Hollis JM, Liu R, Rosenfeld SA, Copeland RA, Decicco CP, Wynn R, Rockwell A, Yang F, Duke JL, Solomon K, George H, Bruckner R, Nagase H, Itoh Y, Ellis DM, Ross H, Wiswall BH, Murphy K, Hillman MC Jr, Hollis GF, Newton RC, Magolda RL, Trzaskos JM, Arner EC: Purification and cloning of aggrecanase-1: a member of the ADAMTS family of proteins. Science 1999, 284:1664-1666

22. Abbaszade I, Liu RQ, Yang F, Rosenfeld SA, Ross OH, Link JR, Ellis DM, Tortorella MD, Pratta MA, Hollis JM, Wynn R, Duke JL, George HJ, Hillman MC Jr, Murphy K, Wiswall BH, Copeland RA, Decicco CP, Bruckner $R$, Nagase $H$, Itoh $Y$, Newton RC, Magolda RL, Trzaskos JM, Hollis GF, Arner EC, Burn TC: Cloning and characterization of ADAMTS11, an aggrecanase from the ADAMTS family. J Biol Chem 1999, 274:23443-23450

23. Somerville RP, Longpre JM, Jungers KA, Engle JM, Ross M, Evanko S, Wight TN, Leduc R, Apte SS: Characterization of ADAMTS-9 and ADAMTS-20 as a distinct ADAMTS subfamily related to Caenorhabditis elegans GON-1. J Biol Chem 2003, 278:9503-9513

24. Chen J, Chung DW, Le J, Ling M, Konkle BA, López JA: Normal cleavage of von Willebrand factor by ADAMTS-13 in the absence of factor VIII in patients with severe hemophilia A. J Thromb Haemost 2013, 11:1769-1772
25. Chen SZ, Ning LF, Xu X, Jiang WY, Xing C, Jia WP, Chen XL, Tang QQ, Huang HY: The miR-181d-regulated metalloproteinase Adamts1 enzymatically impairs adipogenesis via ECM remodeling. Cell Death Differ 2016, 23:1778-1791

26. de Vries PS, van Herpt TT, Ligthart S, Hofman A, Ikram MA, van Hoek M, Sijbrands EJ, Franco OH, de Maat MP, Leebeek FW, Dehghan A: ADAMTS13 activity as a novel risk factor for incident type 2 diabetes mellitus: a population-based cohort study. Diabetologia 2017, 60:280-286

27. Bauters D, Scroyen I, Deprez-Poulain R, Lijnen HR: ADAMTS5 promotes murine adipogenesis and visceral adipose tissue expansion. Thromb Haemost 2016, 116:694-704

28. Bauters D, Cobbaut M, Geys L, Van Lint J, Hemmeryckx B, Lijnen HR: Loss of ADAMTS5 enhances brown adipose mass and promotes browning of white adipose tissue via CREB signaling. Mol Metab 2017, 6:715-724

29. Ataca D, Caikovski M, Piersigilli A, Moulin A, Benarafa C, Earp SE, Guri Y, Kostic C, Arsenijevic Y, Soininen R, Apte SS, Brisken C: Adamts18 deletion results in distinct developmental defects and provides a model for congenital disorders of lens, lung, and female reproductive tract development. Biol Open 2016, 5:1585-1594

30. Jin $\mathrm{H}$, Wang $\mathrm{X}$, Ying J, Wong AH, Li H, Lee KY, Srivastava G, Chan AT, Yeo W, Ma BB, Putti TC, Lung ML, Shen ZY, Xu LY, Langford C, Tao Q: Epigenetic identification of ADAMTS18 as a novel 16q23.1 tumor suppressor frequently silenced in esophageal, nasopharyngeal and multiple other carcinomas. Oncogene 2007, 26: $7490-7498$

31. Aldahmesh MA, Khan AO, Mohamed JY, Alkuraya H, Ahmed H, Bobis S, Al-Mesfer S, Alkuraya FS: Identification of ADAMTS18 as a gene mutated in Knobloch syndrome. J Med Genet 2011, 48: 597-601

32. Peluso I, Conte I, Testa F, Dharmalingam G, Pizzo M, Collin RW, Meola N, Barbato S, Mutarelli M, Ziviello C, Barbarulo AM, Nigro V, Melone M; European Retinal Disease Consortium, Simonelli F, Banfi S: The ADAMTS18 gene is responsible for autosomal recessive early onset severe retinal dystrophy. Orphanet J Rare Dis 2013, 8:16

33. Aldahmesh MA, Alshammari MJ, Khan AO, Mohamed JY, Alhabib FA, Alkuraya FS: The syndrome of microcornea, myopic chorioretinal atrophy, and telecanthus (MMCAT) is caused by mutations in ADAMTS18. Hum Mutat 2013, 34:1195-1199

34. Xiong DH, Liu XG, Guo YF, Tan LJ, Wang L, Sha BY, Tang ZH, Pan F, Yang TL, Chen XD, Lei SF, Yerges LM, Zhu XZ, Wheeler VW, Patrick AL, Bunker CH, Guo Y, Yan H, Pei YF, Zhang YP, Levy S, Papasian CJ, Xiao P, Lundberg YW, Recker RR, Liu YZ, Liu YJ, Zmuda JM, Deng HW: Genome-wide association and follow-up replication studies identified ADAMTS18 and TGFBR3 as bone mass candidate genes in different ethnic groups. Am J Hum Genet 2009, 84:388-398

35. Lopez LM, Bastin ME, Maniega SM, Penke L, Davies G, Christoforou A, Valdés Hernández MC, Royle NA, Tenesa A, Starr JM, Porteous DJ, Wardlaw JM, Deary IJ: A genome-wide search for genetic influences and biological pathways related to the brain's white matter integrity. Neurobiol Aging 2012, 33:1847.e1-1847.e14

36. Li Z, Nardi MA, Li YS, Zhang W, Pan R, Dang S, Yee H, Quartermain D, Jonas S, Karpatkin S: C-terminal ADAMTS-18 fragment induces oxidative platelet fragmentation, dissolves platelet aggregates, and protects against carotid artery occlusion and cerebral stroke. Blood 2009, 113:6051-6060

37. Lu T, Dang S, Zhu R, Wang $\mathrm{Y}$, Nie Z, Hong $\mathrm{T}$, Zhang $\mathrm{W}$ : ADAMTS18 deficiency promotes colon carcinogenesis by enhancing $\beta$-catenin and $\mathrm{p} 38 \mathrm{MAPK} / \mathrm{ERK} 1 / 2$ signaling in the mouse model of AOM/DSS-induced colitis-associated colorectal cancer. Oncotarget 2017, 8:18979-18990

38. Aird AL, Nevitt CD, Christian K, Williams SK, Hoying JB, LeBlanc AJ: Adipose-derived stromal vascular fraction cells isolated from old animals exhibit reduced capacity to support the formation of microvascular networks. Exp Gerontol 2015, 63:18-26 
39. Xu S, Huang Y, Xie Y, Lan T, Le K, Chen J, Chen S, Gao S, Xu X, Shen X, Huang H, Liu P: Evaluation of foam cell formation in cultured macrophages: an improved method with Oil Red O staining and Dil-oxLDL uptake. Cytotechnology 2010, 62:473-481

40. Volloch V, Olsen BR: Why cellular stress suppresses adipogenesis in skeletal tissue, but is ineffective in adipose tissue: control of mesenchymal cell differentiation via integrin binding sites in extracellular matrices. Matrix Biol 2013, 32:365-371

41. Hausman GJ, Wright JT, Richardson RL: The influence of extracellular matrix substrata on preadipocyte development in serumfree cultures of stromal-vascular cells. J Anim Sci 1996, 74: $2117-2128$

42. Varma V, Yao-Borengasser A, Bodles AM, Rasouli N, Phanavanh B, Nolen GT, Kern EM, Nagarajan R, Spencer HJ III, Lee MJ, Fried SK, McGehee RE Jr, Peterson CA, Kern PA: Thrombospondin-1 (TSP1) is an adipokine associated with obesity, adipose inflammation, and insulin resistance. Diabetes 2008, 57:432-439

43. Kong P, Gonzalez-Quesada C, Li N, Cavalera M, Lee DW, Frangogiannis NG: Thrombospondin-1 regulates adiposity and metabolic dysfunction in diet-induced obesity enhancing adipose inflammation and stimulating adipocyte proliferation. Am J Physiol Endocrinol Metab 2013, 305:E439-E450

44. Giancotti FG, Ruoslahti E: Integrin signaling. Science 1999, 285: $1028-1032$

45. Hynes RO: Integrins: bidirectional, allosteric signaling machines. Cell 2002, 110:673-687

46. Assoian RK, Schwartz MA: Coordinate signaling by integrins and receptor tyrosine kinases in the regulation of G1 phase cell-cycle progression. Curr Opin Genet Dev 2001, 11:48-53

47. Howe AK, Aplin AE, Juliano RL: Anchorage-dependent ERK signaling: mechanisms and consequences. Curr Opin Genet Dev 2002, 12:30-35

48. Bost F, Aouadi M, Caron L, Even P, Belmonte N, Prot M, Dani C, Hofman P, Pages G, Pouysségur J, Le Marchand-Brustel Y, Binétruy B: The extracellular signal-regulated kinase isoform ERK1 is specifically required for in vitro and in vivo adipogenesis. Diabetes 2005, 54:402-411

49. Bost F, Aouadi M, Caron L, Binétruy B: The role of MAPKs in adipocyte differentiation and obesity. Biochimie 2005, 87:51-56

50. Ross R, Harker L: Hyperlipidemia and atherosclerosis. Science 1976, 193:1094-1100

51. Piedrahita JA, Zhang SH, Hagaman JR, Oliver PM, Maeda N: Generation of mice carrying a mutant apolipoprotein E gene inactivated by gene targeting in embryonic stem cells. Proc Natl Acad Sci U S A 1992, 89:4471-4475

52. Nicholson AC, Malik SB, Logsdon JM Jr, Van Meir EG: Functional evolution of ADAMTS genes: evidence from analyses of phylogeny and gene organization. BMC Evol Biol 2005, 5:11

53. Brunet FG, Fraser FW, Binder MJ, Smith AD, Kintakas C, Dancevic CM, Ward AC, McCulloch DR: The evolutionary conservation of the A Disintegrin-like and Metalloproteinase domain with Thrombospondin-1 motif metzincins across vertebrate species and their expression in teleost zebrafish. BMC Evol Biol 2015, 15:22

54. Joe B, Saad Y, Dhindaw S, Lee NH, Frank BC, Achinike OH, Luu TV, Gopalakrishnan K, Toland EJ, Farms P, Yerga-Woolwine S, Manickavasagam E, Rapp JP, Garrett MR, Coe D, Apte SS, Rankinen T, Pérusse L, Ehret GB, Ganesh SK, Cooper RS, O'Connor A, Rice $\mathrm{T}$, Weder AB, Chakravarti A, Rao DC, Bouchard C: Positional identification of variants of Adamts 16 linked to inherited hypertension. Hum Mol Genet 2009, 18:2825-2838

55. Quilliot D, Böhme P, Zannad F, Ziegler O: Sympathetic-leptin relationship in obesity: effect of weight loss. Metabolism 2008, 57: $555-562$

56. Leung YM, Kwan CY: Dual vascular effects of leptin via endothelium: hypothesis and perspective. Chin J Physiol 2008, 51:1-6

57. Zeidan A, Purdham DM, Rajapurohitam V, Javadov S, Chakrabarti S, Karmazyn M: Leptin induces vascular smooth muscle cell hypertrophy through angiotensin II- and endothelin-1-dependent mechanisms and mediates stretch-induced hypertrophy. J Pharmacol Exp Ther 2005, 315:1075-1084 